\title{
Preface to the 2012 Edition
}

As I sat five rows back in a Recurrent Training room at the Delta Airlines Stewardess Training Center in the early 1980s, listening to a pilot tell recruits to "smile like you really mean it," I remember noticing the young woman next to me jotting down the advice verbatim. I had already been talking for months to flight attendants from various airlines, interviews that are reflected in this book. So I had a sense of what feelings-anxiety, fear, ennui, resentment, as well as an eagerness to serve-might underlie that smile.

It was that "pinch," or conflict, between such feelings and the pilot's call for authenticity that led me to write down in my own notebook, "emotional labor." Never did I dream that thirty years later, seated at my computer and exploring the Internet, I would discover some 559,000 mentions of "emotional labor" or "labour," and its unpaid form, "emotion work." In their Emotional Labor in the Twenty-first Century, Alicia Grandey, James Diefendorff, and Deborah Rupp discovered over ten thousand mentions of "emotional labor" (or "labour") in academic articles, half of them since 2006, and 506 with the term in the title. ${ }^{1}$

I'm pleased that the idea has caught on but the real reason for such a burst of interest in the subject is, of course, the dramatic rise in the service sector itself. Indeed, as contributors to the American gross domestic product, the manufacturing sector has declined to 12 percent while the service sector has risen to 25 percent. Day-care centers, nursing homes, hospitals, airports, stores, call centers, classrooms, social welfare offices, dental offices-in all these workplaces, gladly or reluctantly, brilliantly or poorly, employees do emotional labor. 
But how much of it do they do? And in what way? R. Cross, W. Baker, and A. Parker call some employees "energizers." The coordinator of hospital volunteers, for example, may try to create a cheerful sense of shared mission. Executive leadership trainers and military trainers may, on the other hand, energize recruits in the spirit of get-out-there-and-defeat-theenemy. Then there are the "toxin handlers"-complaints clerks, bankruptcy court personnel, bank officials dealing with home foreclosures, divorce lawyers, parking meter attendants, and those who specialize in firing workers. (I interviewed one such man for my book, The Time Bind, who described himself as "the man in the black hat.") ${ }^{3}$ Their job is to deliver bad news and, often, to receive the brunt of customer frustration, despair, and rage. And finally there are those who don't so much handle the bad news of others as face a real chance of experiencing pain or loss of their own: soldiers, firefighters, high-rise window-washers, and professional football players, for example.

Other forms of emotional labor require that a person manage a wide range of feeling. The poor salesclerk working in an elite clothing boutique manages envy. The Wall Street stocktrader manages panic. The judge, as legal researcher Terry Maroney shows, is exposed to highly disturbing evidence of atrocities such as maiming, murder, dismemberment, and child rape. He or she must face the task of acknowledging and managing such feelings as horror, outrage, indignation, and pity, all the while maintaining the semblance of impartiality. ${ }^{4}$ Indeed, in leaders we admire, research shows, we seek signs of a capacity both to feel and to regulate those feelings-witness the contempt shown for politicians who weep or panic. ${ }^{5}$

Emotional labor can be hard to recognize. We can, for example, feel schadenfreude, or pleasure at the misfortune of others, a feeling we may be ashamed to have. And our shame can get in the way of the very act of acknowledging that feeling. That's important because it is the pinch between a real but 
disapproved feeling on the one hand and an idealized one, on the other, that enables us to become aware of emotional labor. We may feel lonely at a joyous holiday party, relieved or indifferent at a funeral-and call on ourselves to correct our feelings. These kinds of pinches are of little consequence in certain cultures, and of great consequence in others, for cultures carry different feeling rules. "When I talked about emotional labor to Japanese people, they didn't know what I was talking about," Batja Mesquita, a psychologist at Leuven University in Belgium told me. ${ }^{6}$ The Japanese highly value the capacity to relate to the feelings and needs of others. ${ }^{7}$ So for the Japanese, emotional labor is more built in and therefore harder to see.

Cultural rules are seeing rules. And seeing is a matter of thinking about what we see. Based on our habits of thinking about emotion, we then recognize emotion in ourselves and others in an intricate variety of ways. Ironically, cultures which require the most emotional labor-and may be home to its most highly-trained practitioners - may also be those that inhibit the very recognition of it. Batja's observation leads us to the broader question of how cultural rules inhibit or highlight the very ways we see and think about emotion. Many Japanese do recognize emotional labor, of course (The Managed Heart has been translated into Japanese, Chinese, and Korean). And the emotional labor a Japanese observer may see more keenly than her American counterpart might be that which it takes to uphold the belief in-and indeed fantasy of-the stand-alone individual. ${ }^{8}$

Tellingly, in the United States, the idea of emotional labor has been embraced by business advice gurus as an undiscovered resource and means of competitive advantage, and by labor unions as a cause of burnout, deserving of financial compensation. So where should we look to understand current trends in emotional labor? To the most powerful economic trends of our time, I believe: the profit-seeking drive 
for efficiency, the downsizing of public services, the growing gap between rich and poor, and globalization. Each of these trends fosters situations which call for emotional labor.

Speaking of modern American hospitals, one commentator observed, "Most hospitals used to be community-based and non-profit. Over the last three decades, the trend has been toward for-profits, but whether American hospitals are non-profit or for-profit, increasingly they are run according to business principles." 9 The Beth Israel Hospital in Boston provides one example. It was once a model of primary nursing care, but then merged with another hospital and restructured. Nurses formerly assigned to a particular group of patients were now assigned to "float" from unit to unit, depending on the number of beds filled on a given day. Staff was laid off. Stripped from the nurse's role were tasks now defined as "menial"-positioning a post-surgical patient on a chair, feeding an elderly patient, or helping him to the bathroom. Such tasks were now assigned to untrained, lower-paid workers.

Along the way something else happened too. Encouraging a patient to eat, listening to a patient's story, making a joke, patting an arm-such acts lost importance. They were absent from the medical charts. And these days, "if something isn't on the charts," as one observer noted, "it didn't happen." Emotional labor became invisible.

That didn't mean nurses and aides didn't continue to do it. They did, but from inside a care system in disrepair. As frontline workers, nurses and nurse's aides now had to put a good face on emotion-deaf arrangements. Given fewer nurses to go around, they rushed. They skimped. They were prevented from giving their best. Some tried to detach themselves from the new scene while others managed a loss of pride. We could call this the emotion work of a broken care system. ${ }^{10}$

We can also follow out another trend-the growing gap between rich and poor. For the poor there is the story of doing without service or using inexpensive ones often associated 
with impersonality: dinner at McDonald's, a birthday party at Chuck E. Cheese or the Holiday Inn Wedding Discount Special. But there is also a growing set of services which cater to the very wealthy: the high-end concierge doctor, the maître d' of a fancy restaurant, the room service clerk at an elite hotel who remembers your name and favorite drink, the "experience managers" of the Club-Med vacation. Here the worker personalizes a service, honors the guest, and shields him from loneliness or shame. ${ }^{11}$

We can also follow emotional labor into Sri Lanka, the Philippines, India, Mexico, and elsewhere in the global South as its workers migrate to service jobs in the global North. We can, for example, explore emotional labor as it is connected through a globe-crossing chain of people caring for small children. We could start with the eldest daughter who cares for her younger siblings in a Philippine village while her mother travels to Manila to a weekday job as a nanny to a better-off family. How does the girl feel being the "little mother" of her siblings when others her age play? And her mother, apart weekdays from her own children, caring for the children of a better-off family, how does she feel? And the female employer of the Manila nanny, as is often the case today, may leave her children in the care of husband, mother, and nanny to migrate for years at a time to a job in Los Angeles caring for an American child. Such are the links in a global care chain, with different experiences of emotional labor at every link. ${ }^{12}$

Clients from the global North also travel to service providers in the global South. Many elderly Americans, for example, retire to Mexico. Japanese retire to Thailand and Swedes retire to Spain, sometimes falling sick and dying in the absence of family, in foreign locales. What emotional stories unfold between caregiver and cared-for? Among travelers in what's now called "medical tourism," American infertile couples who wish to have a child can travel to India-where surrogacy is legal, unregulated, and readily available for a tenth of what it would cost in the United States-and engage a sur- 
rogate mother to carry and give birth to their genetic child. ${ }^{13}$ In a visit to the Akanksha Clinic in Anand, India, I was able to talk to some poor Indian surrogates about how it felt to rent their wombs to foreigners. All of them badly needed and wanted the money, but each woman felt differently about her experience. One surrogate, the twenty-eight-year-old wife of a sidewalk vegetable vendor and mother of two children of her own, told me, "Madame-doctor tells us to think of our wombs as carriers, and I do that. But I try to keep from getting too attached to the baby I'm carrying. I remind myself of my own children." Others tried "not to think about it." Another woman bearing a child for a friendly Indian client developed a "little-sister-big-sister" bond with the genetic mother, and thought of the baby she carried as her own, and therefore as a great gift to her "big sister." If the Filipina nanny did the emotional labor of attaching herself to American children who were not her own, the Indian commercial surrogate did the poignant work of detaching herself from a child who was her own.

By exploring relationships which plunge workers into the whirring fan of a global economy-and more-we can apply the perspective described in this book. The flight attendants, bill collectors, and others I describe in these pages might recognize themselves in the lives of millions of others in scores of jobs around the world.

San Francisco

October 2011 


\section{NOTES}

1. Grandey, Alicia, Jim Deifendorff, and Deborah Rupp, eds. Forthcoming 2012. Chapter 1, figure 1, "Search for "emotional labor or labour' using GoogleScholar." In Emotional Labor in the Twenty-first Century: Diverse Perspectives on Emotion Regulation at Work. London: Routledge, Psychology Press. The authors searched in business, social science, and medicine databases for journal articles with "emotional labor" or "labour" anywhere in the paper.

2. Cross, R., W. Baker, and A. Parker. 2003. "What Creates Energy in Organizations?" Sloan Management Review 44:51-57.

3. Frost, P. J., and S. Robinson. 1999. "The Toxic Handler: Organizational Hero and Casualty." Harvard Business Review 77:96-106.

4. Terry A. Maroney. Forthcoming 2012. "Emotional Regulation and Judicial Behavior." California Law Review. See also Terry A. Maroney. 2011. "The Persistent Cultural Script of Judicial Dispassion." California Law Review 99:629, 630, defining "judicial dispassion."

5. Shields, Stephanie A., Leah R. Warner, and MatthewJ. Zawadzki. 2011. "Beliefs About Others' Regulation of Emotion." Paper presented at the International Society for Research on Emotion, July 27, 2011, Kyoto, Japan.

6. Batja Mesquita. 2011. "Emoting as a Contextualized Process." Paper presented at the International Society for Research on Emotion, July 26, 2011, Kyoto, Japan.

7. Yukiko Uchida. 2011. "Emotions as Within or Between People? Cultural Variation in Subjective Well-being, Emotion Expression, and Emotion Inference." Paper presented at the International Society for Research on Emotion, July 26, 2011, Kyoto, Japan.

8. In Japanese The Managed Heart has been translated and published by Sekai Shisosha (Kyoto); in Chinese, by Laureate Books (Taipei); and in Korean by Image Books (Seoul).

9. Interview with elder care manager, for Hochshild, Arlie Russell, The Outsourced Self: Intimate Life in Market Times, forthcoming 2012.

10. Hochshild, Arlie Russell. 2009. "Can Emotional Labor Be Fun?" Work, Organization and Emotion 3 (2).

11. Sherman, Rachel. 2007. Class Acts: Service and Inequality in Luxury Hotels. Berkeley: University of California Press.

12. Ehrenreich, Barbara, and Arlie Russell Hochschild, eds. Global Women: Nannies, Maids, and Sex Workers in the New Economy. New York: Metropolitan/Owl Books, 2012. 
13. The sperm and egg of the American genetic parents were germinated in a petri dish in the Akanksha clinic, and planted in the uterus of the surrogate who then carried the baby to term. My description of this is found in "Childbirth at the Global Crossroads," American Prospect (October 2009): 25-28. Also see "Emotional Life on the Market Frontier," Annual Review of Sociology 37 (2011): 2133; "Afterword," in At the Heart of Work and Family: Engaging the Ideas of Arlie Hochschild, edited by Anita Ilta Garey and Karen V. Hansen, New Brunswick, NJ: Rutgers University Press, 2011, 269-271; and "Through an Emotion Lens," in Theorizing Emotions: Sociological Explorations and Applications, edited by D. Hopkins, J. Kleres, H. Flam, and H. Kuzmics, New York and Frankfurt am Main: Campus Verlag, 2009, 29-38. 